\title{
Enhancing empathy and positive attitude among nursing undergraduates via an in-class virtual reality-based simulation relating to mental illness
}

\author{
Angie Ho Yan Lam*1, Jessie Jingxia Lin ${ }^{2}$, Abraham Wai Hin Wan ${ }^{1}$, Janet Yuen Ha Wong ${ }^{1}$ \\ ${ }^{1}$ School of Nursing, LKS Faculty of Medicine, The University of Hong Kong, Hong Kong S.A.R. \\ ${ }^{1}$ Department of Rehabilitation Sciences, The Hong Kong Polytechnic University, Hong Kong S.A.R.
}

Received: May 27, 2020

DOI: $10.5430 /$ jnep.v10n11p1
Accepted: July 9, 2020

Online Published: July 20, 2020

\begin{abstract}
Objective: The study aims to examine the impact of virtual reality simulation that simulates the experience of psychiatric symptomology associated with mental illness in mental health nursing education.

Methods: A total of 159 nursing students being exposed to an in-class VR simulation completed pre-test measures about empathy and positive attitudes towards mental illness. Narrative feedback was collected to explore the students' perceptions of the VR simulation.

Results: The results indicated a significant increase in the overall empathy and positive attitudes towards mental illness after participating in the in-class VR simulation related to mental illness. Students had a clearer understanding of the patient's experience and difficulties from VR simulation.

Conclusions: In-class VR simulation may play a significant role in enhancing empathetic understanding and positive attitudes towards individuals diagnosed with mental illness.
\end{abstract}

Key Words: Nursing undergraduate, VR simulation, Mental illness, Empathy and positive attitude

\section{BACKGROUND}

Empathetic understanding and attitudes toward patients with mental illnesses are two fundamental ingredients that influence the therapeutic alliance in nurse-patient relationships ${ }^{[1,2]}$ Healthcare professionals are not immune to social prejudices, sometimes share the general public's attitude towards people with mental illness. Studies revealed that undergraduate nursing students had a shortcoming in knowledge about mental illness. ${ }^{[3,4]}$ Nursing students are likely to report fear, anxiety and dread in anticipation of encountering a mentally ill patient. ${ }^{[5]}$ The perception may hinder the patient-nurse relationship and the quality of care in their future practice. ${ }^{[6,7]}$
Clinical skills learning tends to focus heavily on the cognitive and psychomotor domains of learning, while paying limited attention to the affective domain. Affective learning refers to the type of learning that relates the students' emotional and belief system with the establishment of attitude and professional value. ${ }^{[8]}$ In mental health nursing education, it is necessary to consider the affective domain to develop the students' empathic understanding and positive attitude towards mentally ill patients. ${ }^{[9]}$ Experiential learning including simulations and the role-playing scenarios have been frequently applied to change students' stigmatized attitudes. ${ }^{[10,11]}$ Studies demonstrated with role-play scenarios of hearing simulated voices provided students with

\footnotetext{
*Correspondence: Angie Ho Yan Lam; Email: angielam@hku.hk; Address: LKS Faculty of Medicine, School of Nursing, The University of Hong Kong, Hong Kong, China. 
greater empathetic understanding of patients with hallucinations. ${ }^{[10,12,13]}$

In the recent decade, the proliferation of Virtual Reality (VR)based tools adoption in the field of health professions education. Virtual reality is defined as the use of three-dimensional, immersive computer technology to replicate real-life situations. ${ }^{[14]}$ It has expanded exponentially in healthcare education, and may provide a way to simulate a patient's psychological experience into a simulated experience that others can share. ${ }^{[15-21]}$ VR simulation provides an experiential learning for students to better understand how mental health disorders can be and allow them to enter figuratively into the shoes of an individual's experience from mental illness. This learner-centred approach functions on the same basis as the constructivist learning theory which emphasizes one's understanding and knowledge of the world, through experiencing things and reflecting on those experience. ${ }^{[22]}$ Recent VR studies demonstrated that simulating the experience of psychiatric symptoms significantly enhanced the participants' attitudes and empathy towards individuals diagnosed with psychotic disorders and dementia. ${ }^{[22]}$ A literature review on VR simulation in mental health education indicated the potential effectiveness of improving positive attitude and positive learning experience in participants with healthcare backgrounds. ${ }^{[23]}$

The project aims to examine the impact of a virtual realitybased simulation imitating psychiatric experience to be used in the classroom to enhance undergraduate nursing students' empathy, knowledge and positive attitudes towards mental illness. This study hypothesised that there would be an increase in positive attitudes and empathy towards mental illness after the in-class VR simulation.

\section{Methods}

\subsection{Setting and sample}

A non-probability convenience sample was used. The study was conducted as part of the pre-licensure baccalaureate nursing program at a university in Hong Kong during 2018-2019 semester. Approval was obtained from the university's Institutional Review Board (UW 18-332). The inclusion criteria for the study were (1) participants must be fourth year nursing students who were enrolled in the course Mental Health Nursing, which is a compulsory subject for the pre-licensure baccalaureate nursing program, (2) willingness to participate in the simulation test.

Recruitment occurred during the first week of the course. The course coordinator explained the purpose of the study and that participation was voluntary. A written information sheet was distributed to supplement the information of VR simulation. No penalty was given to the students who did not wish to participate in the study; nor was any compensation provided to those who participated. A total of 159 students consented to participate in this study from the class with 208 students. The participation rate was $76.4 \%$.

\subsection{Development of VR simulation}

Three VR simulation videos were developed to replicate the lived-experience of patients with psychosis, anxiety disorder, and mood disorder, respectively. Each VR simulation lasted for 5 to 7 minutes. Throughout the VR simulation, the students would experience what the patient sees, thinks, and hears with psychiatric symptoms filled life. The simulation also revealed the unseen difficulties of the clients, such as misunderstanding and stigma from society. All simulation videos were created with the following components to achieve the learning experiences:

- Realistic living environment

- Sensory simulation imitating symptomology of the mental illnesses, such as hallucination, delusion or sensory overload - Perception, thoughts and feelings as the first person

- The known stigma from society

Two experienced psychiatric nurses designed the video vignettes based on the information from case reports and literature. These psychiatric nurses interviewed patients with psychotic disorder, depression and anxiety disorder to inform the symptoms and experiences presented in the virtual reality simulation. Patients' and mental health expert's opinions developed and revised the drama scripts to more clearly reflect the real status of patient's experiences.

The teaching team also worked with e-learning technology experts from Technology-Enriched Learning Initiative (TELI) to figure out the best way to simulate the experiences that the clients would struggle with. The team used 360 degree VR video shooting to film a number of scenes to explore the standardized patient's life in school, in the restaurant, and at home. A basic VR cardboard, which is a simple affordable paper-made headset for the immersive experience, was used to create the VR environment in a large class.

\subsection{Procedure}

The VR simulation was integrated into the class of Mental Health Nursing which contained three lectures about psychosis, anxiety disorder, and mood disorder, respectively. Commencing, the students received an hour lecture which provided an overview on various forms of mental illness and relevant information such as signs and symptoms, causes and risk factors. After the theoretic input, the students were engaged in the in-class VR simulation. The students were expected to identify the clinical presentation, perception and 
daily difficulties associated with individuals with these disorders. After the exposure to each VR simulation, there was a 15-minute debriefing that focused on discussion and reflection about the experience that the patient encountered, and the student's personal experience towards mental illnesses (see Figure 1). Online discussion platform Mentimeter and the Gibbs reflective cycle were adopted to facilitate the discussion about the feelings and thoughts related to the learning experience, and what they would do differently in caring for these patients in the future. ${ }^{[24]}$

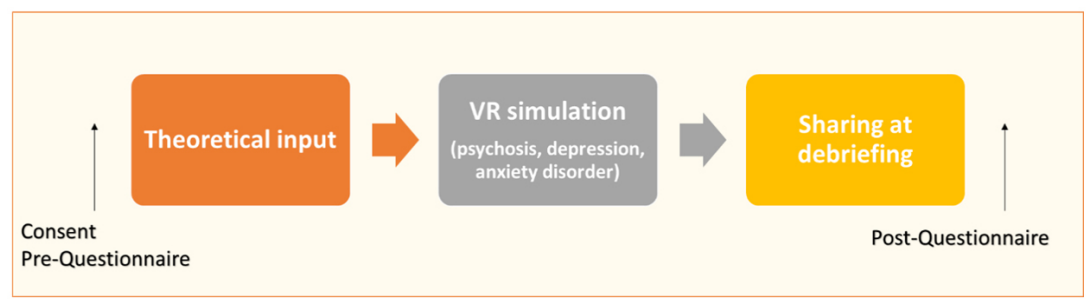

Figure 1. Procedure of VR simulation

\subsection{Measures}

For standard demographic information, specific characteristics of participants including previous experience of close contact with mental health patients, and receiving relevant mental health training, were collected.

\subsubsection{Chinese-language Empathy Scale in Patient Care (ES-PC)}

The ES-PC is a 23-item questionnaire that measures the level of empathy with three subscale: intellectual empathy (7 items; $5.71 \%$ of total variance), affective empathy (7 items; $10.99 \%$ ), behavioural empathy ( 9 items; $44.73 \%$ ). Intellectual empathy describes an individual's capacity to understand another person's feelings and emotions. ${ }^{[25,26]}$ Affective empathy describes an individual affectively feels and internalizes the emotion experienced by another person. ${ }^{[25,26]}$ Following that, behavioural empathy involves the outward expression of understanding the other person's feeling by observable gestures. ${ }^{[25,26]}$ The questionnaire is a 9-point Likert scale, ranging from 9 (Totally agree) to 1 (Totally disagree). The study indicated a good internal consistency with the Cronbach's $\alpha$ coefficients value for the 3 subscales, and the overall scale ranged from .87 to .94 . Evidence of concurrent validity also showed a good external validity with test-retest correlation coefficient for the entire scale $r=.89 .{ }^{[25]}$

\subsubsection{Chinese-version Attitudes toward Mental Illness (CAMI)}

CAMI is an 11-item self-report scale questionnaire which examines the negative attitudes and recovery outcomes towards mental illness. The items are scored on a 5-point Likert's scale ranging from 5 (strongly agree) to 1 (strongly disagree), with higher score indicating a more positive attitude towards mental illness. The scorings on item 1-4 are reversed to avoid a response bias. The Cronbach's $\alpha$ coefficients indicated a good internal consistency (coefficient $\alpha:$.75-.81), and appropriate construct validity and cross validity $\left(\chi^{2}=105.31\right.$, GFI Published by Sciedu Press
$=.92, \mathrm{IFI}=.91, \mathrm{CFI}=.91) .{ }^{[27,28]}$

\subsubsection{Chinese-version Mental Health Knowledge Ques- tionnaire (MHKQ)}

MHKQ is a 20-item self-report true and false questionnaire. The first 16 questions assess the individual basic knowledge of mental health and the remaining items assess the awareness of mental health promotion issues. One point is given for each correct answer. The total score ranges from 0 to 20 , with higher scores implying a higher 'mental health literacy'. The psychometric testing showed that the internal consistency of the Cronbach's $\alpha$ coefficients ranges from 0.62 to $0.73 .{ }^{[29,30]}$ The exploratory factor analysis yielded a three-factor solution and covers three aspects of mental health knowledge, including the characteristics of mental health and mental disorders, the epidemiology of mental disorders, and awareness of mental health promotion has Cronbach's $\alpha$ coefficients ranging from 0.62 to $0.67 .{ }^{[29]}$

\subsubsection{Satisfaction survey}

At post VR simulation, students were served with a satisfactory questionnaire containing six 5-point Likert scale questions and three narrative questions to collect their opinion and feedback to VR simulation. The questions covered a wide range of judgements related to effectiveness of VR simulation education, including learning needs, learning outcomes, resources support, the logistic arrangement, the satisfaction, strength, and weakness of the VR simulation, and the suggestions for improvement.

\subsection{Data Analysis}

Quantitative data analysis was performed using SPSS version 25. Descriptive statistics were used to provide information about the demographic characteristics of the participants. A series of paired $t$-test was used to explore the change between the baseline and post-test on each dependent variable (empathy, attitude and knowledge) in overall participants 
and participants with specific characteristics (close contact with mental health patients, and receiving mental health relevant training). The reliability of the instruments has also been assessed through Cronbach's Alpha to determine the internal consistency. Cronbach (1951) suggested that a Cronbach's Alpha ranges between 0.6-0.7 indicates a fair internal consistency reliability, 0.7 and 0.8 indicates an acceptable reliability coefficient, ranged between 0.8 and 0.9 indicates a good reliability coefficient, and Cronbach's Alpha larger than 0.9 indicates an excellent reliability coefficient. ${ }^{[31]}$

The narrative feedback collected in the evaluation survey was qualitatively analyzed as outlined by Miles et al. ${ }^{[32]}$ to draw new insight into students' opinion about the VR simulation. All narrative feedbacks were directly entered into the computer. The researcher read and re-read the feedback to gain a sense of wholeness, and thereafter, there would be a line-byline coding of text according to its meaning and content. The research team then discussed and verified the coding again to ensure it truly reflect the key themes of the responses. The frequency of codes was then counted to identify the most frequently reoccurring themes.

\section{RESUlt}

One hundred and fifty-nine fourth year nursing students taking the course Mental Health Nursing were enrolled in the study of the in-class VR simulation. The students average age was 21.57 (SD 1.12, range 20-29) and the population was female-dominated $(69.8 \%)$. Thirty-nine percent of the participants had attended mental health-related courses before their participation, and $28.9 \%$ of them had close contact with people with mental illness (see Table 1).

Table 1. Demographic characteristics of the participants (n =159)

\begin{tabular}{lc}
\hline Characteristic & Mean (SD) \\
\hline Age (years) & $21.57(1.12)$ \\
Gender & $48(30.2)$ \\
Male & $111(69.8)$ \\
Female & $63(39.6)$ \\
Attended mental health related course \\
Yes & $96(60.4)$ \\
No & \\
Close contact with MI & $46(28.9)$ \\
Yes & $113(71.1)$ \\
No
\end{tabular}

The results demonstrated that there was a significant increase in the overall empathy, both behavioral and intellectual empathy after participating in the in-class VR simulation (see Table 2). Moreover, affective empathy displayed no significant difference before and after the in-class VR simulation. The subgroup results also revealed that there was a significant empathy increase in all students regardless of previously attending mental illness training (see Table 3). The subgroup results also revealed that there was a significant empathy increase in the students who had no close contact with mental illness (see Table 4). The ES-PC demonstrated strong internal consistency reliability in total score ( $\alpha=.92-.94)$, behavioral subscales $(\alpha=.93)$, affective subscale $(\alpha=.92-.93)$ and intellectual subscale ( $\alpha=.89-.91)$ in this study.

Table 2. Mean score of outcome measures $(n=159)$

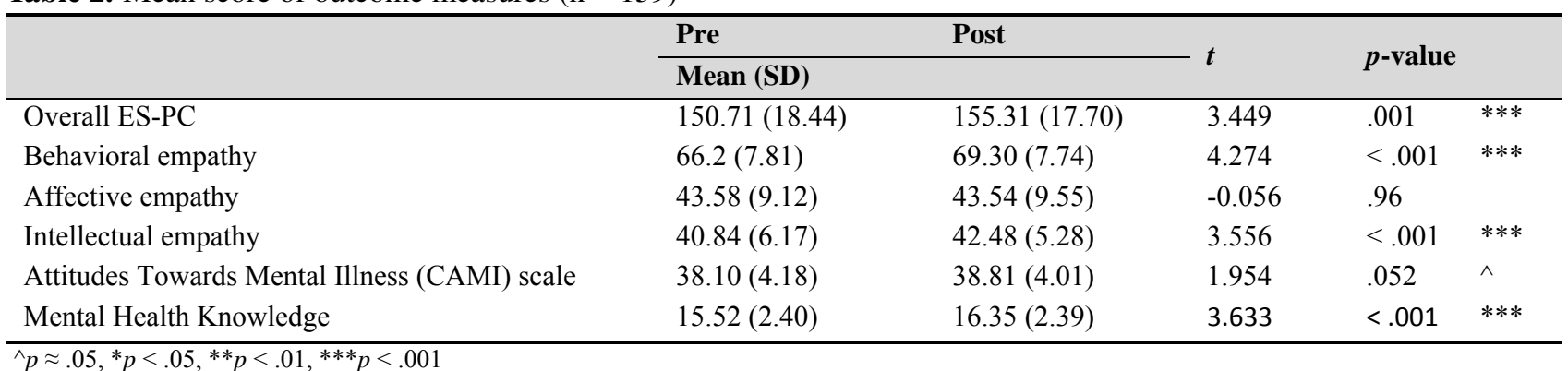

Table 3. Mean score of subgroup: Previous experience in receiving mental health training

\begin{tabular}{|c|c|c|c|c|}
\hline & \multicolumn{4}{|c|}{ Attended training related to mental illness } \\
\hline & \multicolumn{2}{|l|}{ Yes $(n=63)$} & \multicolumn{2}{|l|}{ No $(n=96)$} \\
\hline & Pre & Post & Pre & Post \\
\hline & Mean (SD) & & Mean (SD) & \\
\hline Overall ES-PC & $151.03(19.44)$ & $156.22 * *(16.79)$ & $150.50(17.85)$ & $154.72 *(18.33)$ \\
\hline Attitudes Towards Mental Illness (CAMI) scale & $38.18(4.5)$ & 38.81 (4.53) & 38.04 (3.97) & $38.80(3.66)$ \\
\hline Mental Health Knowledge & $15.98(2.43)$ & 16.40 (2.59) & $15.21(2.39)$ & $16.32 * * *(2.26)$ \\
\hline
\end{tabular}


Regarding attitudes towards mental illness, there was a marginal increase in the improvement on attitudes after the participation in the in-class VR simulation (see Table 2). Interestingly, the students who had previous close contact with mental illness demonstrated a significant increase in attitudes towards mental illness ( $\mathrm{MD}=1.33, p=.048$ ), while there was no significant increase in the attitude of students who had no previous close contact with mentally ill indi- viduals ( $p=.295$ ) (see Table 4$)$. The CAMI adopted in the study demonstrated a fair internal consistency reliability ( $\alpha$ $=.61-.69)$.

Overall, the result demonstrated that there was a significant increase in mental health knowledge after the students' participation in VR mental health simulation (see Tables 2 \& 4).

Table 4. Mean score of subgroup: Close contact with mental health patients

\begin{tabular}{|c|c|c|c|c|}
\hline & \multicolumn{4}{|c|}{ Close contact with mental patients } \\
\hline & \multicolumn{2}{|l|}{ Yes $(n=46)$} & \multicolumn{2}{|l|}{ No $(n=113)$} \\
\hline & Pre & Post & Pre & Post \\
\hline & Mean (SD) & & Mean (SD) & \\
\hline Overall ES-PC & $154.65(20.43)$ & 157.39 (18.59) & $149.11(17.41)$ & $154.47 * *(17.33)$ \\
\hline Attitudes Towards Mental Illness (CAMI) scale & $37.54(4.43)$ & $38.87 *(3.96)$ & $38.32(4.07)$ & 38.78 (4.05) \\
\hline Mental Health Knowledge & $15.54(2.81)$ & $16.22(2.41)$ & $15.50(2.23)$ & $16.41 * * *(2.39)$ \\
\hline
\end{tabular}

${ }^{*} p<.05,{ }^{* *} p<.01,{ }^{* * *} p<.001$

The satisfaction questionnaires showed that over $65 \%$ of the respondents agreed that the in-class VR simulation was an appropriate pedagogy that met the training needs, and was able to enhance their understanding and attitude towards mental illness. $76 \%$ of the respondents expressed satisfaction towards the VR simulation (see Figure 2).

\begin{tabular}{|c|c|c|c|c|c|}
\hline & \multirow[b]{2}{*}{$\begin{array}{l}\text { Agreement with the following } \\
\text { statements: }\end{array}$} & \multicolumn{2}{|c|}{ Based on all respondents } & \multirow[b]{2}{*}{ Neutral } & \multirow[b]{2}{*}{ Disagree } \\
\hline & & Strongly agree & $\begin{array}{l}\text { Agree } \\
68 \%\end{array}$ & & \\
\hline SQ1 & VR simulation meets your training needs & $10 \%$ & $58 \%$ & & $26 \%$ \\
\hline SQ2 & $\begin{array}{l}\text { After the VR simulation, you have an } \\
\text { increased understanding about mental } \\
\text { illness }\end{array}$ & $14 \%$ & $\begin{array}{r}63 \% \\
76 \%\end{array}$ & & $19 \%$ \\
\hline SQ3 & $\begin{array}{l}\text { After the VR simulation, you have a more } \\
\text { positive attitude about mental illness }\end{array}$ & $11 \%$ & $65 \%$ & & $21 \%$ \\
\hline SQ4 & This teaching method used is appropriate & $18 \%$ & $76 \%$ & & $22 \%$ \\
\hline SQ5 & $\begin{array}{l}\text { The logistic arrangement of the VR } \\
\text { simulation (e.g. lecture input, VR video in } \\
\text { classroom etc) is appropriate }\end{array}$ & $18 \%$ & $\begin{array}{l}57 \% \\
76 \%\end{array}$ & & $24 \%$ \\
\hline SQ6 & You are satisfied with this VR simulation & $14 \%$ & $62 \%$ & & $22 \%$ \\
\hline
\end{tabular}

Figure 2. Satisfactory questionnaire

\subsection{Narrative feedback}

Thirty-five students provided narrative feedback for the inclass VR simulation. The identified themes from the written reflections and the frequency of the most common themes are reported in Table 5.

One predominant theme that emerged was that students found the in-class VR simulation to be interesting and good learn- ing experiences $(n=17)$. The students' expressions captured are 'very interesting' and 'it made the class more interesting and interactive'.

The second predominant theme was 'get a real understanding of the patient's experience and difficulties' $(n=8)$. Students reported the in-class VR simulation helped them to gain more understanding of the patient's viewpoint and situation. 
One student reported that it is ' $\operatorname{good}$ to experience the feelings/thoughts of the patients'. Another student also made a similar statement, 'able to put ourselves into patient's perspectives, knowing and feeling how the signs and symptoms are like'.

Table 5. Identified Themes and Frequency from Written feedback $(\mathrm{n}=35)$

- Interesting and Good learning experience $(n=17)$

- Get a real understanding of patients' experience and difficulties $(\mathrm{n}=8)$

- Facilitate the learning process $(n=2)$

- Consider VR as the future of education $(n=1)$

- Technical problems $(\mathrm{n}=6)$

- Physical discomfort $(\mathrm{n}=3)$

- Unpleasant experience $(\mathrm{n}=3)$

- Same as watching a video $(\mathrm{n}=3)$

- Adding therapeutic communication in VR to equip the communication skill $(\mathrm{n}=1)$

Two students found that in-class VR simulation facilitated their learning process. They reflected that they found it easy to remember the characteristics, signs and symptoms of the mental illness, as well as understanding how they appeared in reality. One student expressed the importance of VR technology in education, and 'considers VR as the future of education, especially in the medical and nursing discipline'.

On the other hand, there were negative comments received. The predominant theme emerged was technical problems. Students complained that the video took too long to load, and the quality of the video was not good enough. The other theme that emerged was physical discomfort. Three students reported feeling dizzy after the VR simulation. Three students expressed unpleasant experiences including timewasting and annoying experience to explore VR under the stressful classroom environment. Another three students expressed that the experience was similar to watching the video without VR platform. One student suggested further development in using VR to equip the therapeutic communication skill.

\section{Discussion}

The current study examined the effectiveness of using inclass VR simulation in mental health education to improve empathetic understanding, and positive attitudes of prelicensure baccalaureate nursing students. The results demonstrated that the participants endorsed significantly higher scores on overall empathy and attitudes after exposing VR simulation in the classroom. The results supported our study's hypothesis and is consistent with previous research in- vestigating the effect of VR simulation in enhancing empathy and attitudes towards mental illness in health professionals training. ${ }^{[22,23,33]}$ The students also demonstrated significant improvement in the empathy subscales including intellectual and behavioral empathy after the in-class VR simulation. The results reflect that in-class VR simulation might enhance the student's capability into the patient's internal world and affirm their feelings and willingness to employ the behavioural skills, or observable gestures, to demonstrate their empathetic understanding to patients. The qualitative results also echoed the students' engagement in putting themselves into the patient's experiences. These findings support that in-class VR simulation in mental health education might establish student's affective elements related to quality nursing care such as empathy, attitudes and professional value towards mental illness.

The results showed that the students did not change in affective empathy after receiving the in-class VR simulation. Affective empathy refers to emotional engagement, or affectively feeling the same emotions as the client (Williams et al., 2010). Healthcare professionals traditionally preserved affective empathy to avoid over-identification with patients/family, and blurring of the professional boundaries. ${ }^{[34]}$ Recent studies also discovered that healthcare students decreased their affective empathy along the clinical training, so as to preserve their own emotional integrity and the finite cognitive resources required to manage new and complex clinical situations. ${ }^{[35,36]}$ The affective empathy shifted to a greater capacity towards the utilization of cognitive empathy, and thus, the overall empathy declined. ${ }^{[35,36]}$ Interestingly, the result in this study reflected that only students who had previous close contact to people with mental illness significantly improved in positive attitudes towards mental illness ( $p=$ .048 ), while the students who had no previous close contact to people with mental illness showed no improvement in their attitudes towards mental illness $(p=.295)$. This result might indicate that the in-class VR simulation improved the attitudes of students who had pre-existing perception, or were even bias or prejudge towards people with mental illness. Mental illness is highly stigmatized in Hong Kong under the influence of Confucian culture. ${ }^{[37]}$ Previous study found that people with close contact to these patients, such as the caregiver, held intense negative attitudes towards the disorder. ${ }^{[38]}$ Caregivers perceived mentally ill people to be violent and dangerous, as a punishment for past behaviours of the family, or as a reflection of poor discipline in family. ${ }^{[38,39]}$ Close companions were also distressed by patient's disturbing psychiatric disorder, lack of employment, poor treatment compliance, financial burden, and their interruption of social activities. ${ }^{[37,38]}$ The result of this study demonstrates 
that VR simulation imitating psychiatric symptoms might be helpful in building positive attitudes towards mental illness among the patient's close companions. Future studies may explore the role of VR simulation in promoting positive and satisfactory attitudes among patient's close companion, such as caregivers.

Students also indicated the negative experiences of VR simulation, which include technical problems and the physical discomfort symptoms, such as cybersickness, which was consistent with the prominent complaints in previous studies on VR education. ${ }^{[40-42]}$ The common symptoms are general discomfort, nausea, vomiting, pallor, and drowsiness. ${ }^{[42]}$ Technical problems and cybersickness hindered the knowledge and skill acquisition, as well as the learner's attitudes towards this technology. The negative aspects may even increase the dropout rate from the immersive learning activities. ${ }^{[42,43]} \mathrm{Cy}$ bersickness is caused by a mismatch between the sensory systems involved in motion perception. A higher-resolution and high-performance head-mounted VR gear may minimise the cybersickness. ${ }^{[44]}$ This study also revealed other unpleasant experiences during the exposure of VR simulation, such as time-wasting, annoying and disturbing. Students' negative experience was associated with feelings of strain and stress with the use of VR technologies. ${ }^{[45]}$ Meanwhile, the 3D immersive learning environment have been found to be useful to promote better knowledge acquisition, motivation and active engaging in learning, ${ }^{[42,43,46]}$ it is worthy to further explore the factors hindering the use of VR system, and the solutions to minimize the barriers of using VR in healthcare education.

Several limitations were noted in the current study. First, the study used non-controlled and non-randomised design which undermines the validity of the study result. Second, the results were influenced by many external factors; for example, the principal investigator was the teacher who led the in-class VR simulation, this instance might inflate the intervention effect. The attitudes of the faculty administering the in-class VR simulation might also influence the student's response.
Third, the VR simulation was arranged after the theoretical input in the course 'Mental Health Nursing'. Thus, it is doubtful if the positive finding was purely the result of the VR simulation, the lecture input, or the interaction effect of the lecture and VR simulation. Fourth, the study did not conduct the usability testing of this newly developed virtual reality experience. The technology acceptance model should be adopted in the study to evaluate the students' perception in the usefulness and ease-of-use of this VR simulation. Future studies with full experimental design are needed to address these limitations.

\section{Conclusion}

In conclusion, this study suggests that the in-class VR simulation may play a role in enhancing empathetic understanding and positive attitudes towards individuals diagnosed with mental illness. The results suggest that the in-class VR simulation may help students to develop the core nursing competencies necessary to meet the needs of the care. The findings of the current study have significant implications for nursing educators who wish to promote student's affective dispositions with regard to high-quality care in a safe and practical way, as well as for nursing students who are preparing to establish therapeutic alliance and high-quality care in their future practice. The results also inform future research with direction for the development of VR in nursing education to cover the learning objectives in cognitive, affective and psychomotor domains.

\section{ACKNOWLEDGeMENTS}

This project was supported by Teaching Development Grant (Project no. 18/683) of University Grants Committee, Hong Kong. We also wish to gratefully acknowledge the support from Technology-Enriched Learning Initiative of the University of Hong Kong for the design of education materials.

\section{CONFLICTS OF INTEREST Disclosure}

The authors declare that there is no conflict of interest.

\section{REFERENCES}

[1] Reynolds WJ, Scott B, Jessiman WC. Empathy has not been measured in clients' terms or effectively taught: a review of the literature. Journal of Advanced Nursing. 1999; 30(5): 1177-85. PMid:10564417 https://doi.org/10.1046/j.1365-2648.1999.01191.x

[2] Mousa MAEA. Empathy toward Patients with Mental Illness among Baccalaureate Nursing Students: Impact of a Psychiatric Nursing and Mental Health Educational Experience. Journal of Education and Practice. 2015; 6(24): 98-107. https://doi.org/10.12934/jkp $\operatorname{mhn} .2015 \cdot 24 \cdot 2 \cdot 107$

[3] Happell B, Gaskin CJ. The attitudes of undergraduate nursing students towards mental health nursing: a systematic review. Journal of Clinical Nursing. 2013; 22(1-2): 148-158. PMid:23170825 https://doi.org/10.1111/jocn. 12022

[4] van der Kluit MJ, Goossens PJ. Factors influencing attitudes of nurses in general health care toward patients with comorbid mental illness: an integrative literature review. Issues Mental Health Nursing. 2011; 32(8): 519-27. PMid:21767254 https://doi.org/10.3109/01 
612840.2011 .571360

[5] Langham G, Jones M, Terry A. Transforming future nurses through simulation in mental health nursing. Journal of Nursing Education and Practice. 2016. https : //doi .org/10.5430/jnep.v7n4p96

[6] Hamdan-Mansour A, Wardam 1. Attitudes of Jordanian Mental Health Nurses Toward Mental Illness and Patients with Mental Illness. Issues in Mental Health Nursing. 2009; 30(11): 705-711. PMid:19874099 https://doi.org/10.1080/01612840903131792

[7] Poreddi V, et al. Undergraduate Nursing Students' Attitudes towards Mental Illness: Implications for Specific Academic Education. Indian Journal of Psychological Medicine. 2014; 36(4): 368-72. PMid:25336767 https ://doi.org/10.4103/0253-7176.1407 01

[8] Taylor LD. The Affective Domain in Nursing Education: Educators' Perspectives, in College of Nursing. University of WisconsinMilwaukee. 2014.

[9] Williams J, Stickley T. Empathy and nurse education. Nurse Education Today. 2010; 30(8): 752-755. PMid:20381220 https : //doi.org/10.1016/j.nedt.2010.01.018

[10] Bunn W, Terpstra J. Cultivating Empathy for the Mentally Ill Using Simulated Auditory Hallucinations. Academic Psychiatry. 2009; 33(6): 457-460. PMid:19933888 https ://doi .org/10.1176/ap pi.ap.33.6.457

[11] Sideras S, et al. Impact of a Simulation on Nursing Students' Attitudes Toward Schizophrenia. Clinical Simulation in Nursing. 2015; 11(2): 134-141. https://doi.org/10.1016/j.ecns.2014.11 .005

[12] Skoy ET, et al. Use of an Auditory Hallucination Simulation to Increase Student Pharmacist Empathy for Patients with Mental Illness. American Journal of Pharmaceutical Education. 2016; 80(8): 142 PMid:27899838 https ://doi.org/10.5688/ajpe808142

[13] Fossen P, Stoeckel PR. Nursing Students' Perceptions of a Hearing Voices Simulation and Role-Play: Preparation for Mental Health Clinical Practice. Journal Nursing Education. 2016; 55(4): 203-8. PMid:27023889 https ://doi.org/10.3928/01484834-20160 316-04

[14] Lopreiato JO. Healthcare Simulation Dictionary. Rockville, MD.: Agency for Healthcare Research and Quality. 2016.

[15] Galloway SJ. Simulation techniques to bridge the gap between novice and competent healthcare professionals. 2009; 14(2).

[16] Ryall T, Judd BK, Gordon CJ. Simulation-based assessments in health professional education: a systematic review. 2016.

[17] Cantrell MA, et al. The evidence in simulation-based learning experiences in nursing education and practice: an umbrella review. 2017; 13(12): 634-667. https ://doi.org/10.1016/j.ecns. 2017.08 .004

[18] Brown AMJCSIN. Simulation in undergraduate mental health nursing education: A literature review. 2015; 11(10): 445-449. https: //doi.org/10.1016/j.ecns.2015.08.003

[19] Akaike M, et al. Simulation-based medical education in clinical skills laboratory. 2012; 59(1, 2): 28-35. PMid:22449990 https: //doi.org/10.2152/jmi.59.28

[20] Cooper S, et al. Simulation based learning in midwifery education: a systematic review. 2012; 25(2): 64-78. PMid:21489894 https://doi.org/10.1016/j.wombi.2011.03.004

[21] Zendejas B, et al. State of the evidence on simulation-based training for laparoscopic surgery: a systematic review. 2013; 257(4): 586-593. PMid:23407298 https://doi.org/10.1097/SLA.0b013e3182 $88 \mathrm{c} 40 \mathrm{~b}$

[22] Formosa NJ, et al. Testing the efficacy of a virtual reality-based simulation in enhancing users' knowledge, attitudes, and empathy relating to psychosis. Australian Journal of Psychology. 2018; 70(1): 57-65 https://doi.org/10.1111/ajpy.12167

[23] Wan WH, Lam AHY. The Effectiveness of Virtual Reality-Based Simulation in Health Professions Education Relating to Mental Illness: A Literature Review. Health. 2019; 11(06): 646-660. https : //doi.org/10.1111/ajpy.12167

[24] Gibbs G. Learning by Doing: A guide to teaching and learning methods. Further Education Unit. Oxford: Oxford Polytechnic; 1988.

[25] Wang YH, Liao HC. Development and validation of the Empathy Scale in Patient Care: Chinese version. Social Behavior and Personality: an International Journal. 2017; 45(8): 1271-1280. https ://doi .org/10.2224/sbp. 6005

[26] Tamayo CA, Rizkalla MN, Henderson KK. Cognitive, Behavioral and Emotional Empathy in Pharmacy Students: Targeting Programs for Curriculum Modification. Frontiers in Pharmacology. 2016; 7: 96-96. PMid:27148055 https://doi.org/10.3389/fphar.2016.000 96

[27] Kuo YP, et al. Developing and testing the validity and reliability of the Chinese version attitudes toward mental illness scale in a sample of senior high school students. Hu Li Za Zhi. 2014; 61(6): 48-56.

[28] Kobau R, et al. Attitudes about mental illness and its treatment: validation of a generic scale for public health surveillance of mental illness associated stigma. Community Mental Health Journal. 2010; 46(2): 164-76. PMid:19330448 https://doi.org/10.1007/s1 0597-009-9191-x

[29] Yu Y, et al. Assessment of mental health literacy using a multifaceted measure among a Chinese rural population. BMJ Open. 2015; 5(10): e009054-e009054. PMid:26438139 https ://doi.org/10.1136/ bmjopen-2015-009054

[30] Zhong BL, et al. Relia-bility and validity of mental health knowledge questionnaire for middle school students. Chinese Journal of School Health. 2011; 32(1): 49-50.

[31] Cronbach LJ. Coefficient Alpha and the Internal Structure of Tests. Psychometrika. 1951; 16(3): 297-334. https ://doi.org/10.100 7/BF02310555

[32] Miles MB, Huberman M, Saldana J. Qualitative Data Analysis: A Methods Sourcebook. 3rd ed. Thousand Oaks, CA: SAGE Publications; 2013.

[33] Yellowlees PM, Cook JN. Education about hallucinations using an internet virtual reality system: a qualitative survey. Acad Psychiatry. 2006; 30(6): 534-9. PMid:17139026 https://doi.org/10.117 6/appi.ap.30.6.534

[34] Matthews D, Suchman A, Branch W. Making connections - enhancing the therapeutic potential of patient-clinician relationships. Annals Of Internal Medicine. 1993; 118(12): 973-977. PMid:8489112 https : //doi .org/10.7326/0003-4819-118-1 2-199306150-00010

[35] Youssef FF, et al. An exploration of changes in cognitive and emotional empathy among medical students in the Caribbean. International Journal of Medical Education. 2014; 5: 185-192. PMid:25341229 https://doi.org/10.5116/ijme.5412.e641

[36] Aomatsu M, et al. Medical students' and residents' conceptual structure of empathy: A qualitative study. Education for Health. 2013; 26(1): 4-8. PMid:23823666 https : //doi .org/10.4103/1357-6 283. 112793

[37] Wong D. Stress factors and mental health of carers with relatives suffering from schizophrenia in Hong Kong: implications for culturally sensitive practices. British Journal of Social Work. 2000; 30(3): 365-382. https://doi .org/10.1093/bjsw/30.3.365

[38] Wong DF, et al. Family burdens, Chinese health beliefs, and the mental health of Chinese caregivers in Hong Kong. Transcult Psychiatry. 
2004; 41(4): 497-513. PMid:15709648 https://doi.org/10.1 $177 / 1363461504047932$

[39] Neupane D, et al. Caregivers' Attitude towards People with Mental Illness and Perceived Stigma: A Cross-Sectional Study in a Tertiary Hospital in Nepal. PLoS One. 2016; 11(6): e0158113. PMid:27336391 https://doi.org/10.1371/journal.pone.0 158113

[40] Kidd LI, Knisley SJ, Morgan KI. Effectiveness of a second life((R)) simulation as a teaching strategy for undergraduate mental health nursing students. J Psychosoc Nurs Ment Health Serv. 2012; 50(7): 28-37. PMid:22694785 https://doi.org/10.3928/02793695 -20120605-04

[41] Weech S, Kenny s, Barnett-Cowan M. Presence and Cybersickness in Virtual Reality Are Negatively Related: A Review. Front Psychol. 2019; 10: 158. PMid:30778320 https://doi.org/10.3389/fp syg. 2019.00158

[42] Jensen L, Konradsen F. A review of the use of virtual reality headmounted displays in education and training. Education and Informa- tion Technologies. 2017; 23(4): 1515-1529. https ://doi.org/10 .1007/s10639-017-9676-0

[43] Polcar J, Horejsi P. Knowledge Acquisition and Cyber Sickness: A Comparison of Vr Devices in Virtual Tours. MM Science Journal. 2015; 2015(02): 613-616. https://doi.org/10.17973/MMS J.2015_06_201516

[44] Kemeny A, et al. New VR Navigation Techniques to Reduce Cybersickness. The Engineering Reality of Virtual Reality. 2017; 48-53.

[45] Janssen D, et al. Towards Measuring User Experience, Activation and Task Performance in Immersive Virtual Learning Environments for Students, in Immersive Learning Research Network. ILRN. 2016, A. C., et al., Editors. 2016, Springer, Cham. p. 45-58. https://doi.org/10.1007/978-3-319-41769-1_4

[46] Huang HM, Rauch U, Liaw SS. Investigating learners' attitudes toward virtual reality learning environments: Based on a constructivist approach. Computers \& Education. 2010; 55(3): 1171-1182. https://doi.org/10.1016/j.compedu.2010.05.014 